\title{
Evaluation of network service model based on network convergence
}

\author{
Jing Zhang ${ }^{*}$ and Xiaoping Liu
}

\begin{abstract}
Technologies such as Bluetooth, RFID, WiFi, 4G, and the Internet of things are mutually converged with ADSL and fiber to the home network. Users can get information in the forms of word, voice, images, etc. through ubiquitous networks including the fixed telephone, the mobile telephone, the television, the computer, and diversified informational zed terminal equipment. Ubiquity informatization may be the trend of future network development, which is the development direction of the ubiquitous intelligent comprehensive network information society. Its physical representation is the appearance of ubiquitous network or the named universal network. It represents the ubiquitous prosperity that all people, all organizations, and industries can get benefits from the ubiquity informatization. This article studies the internal and external structures of network service model and introduces technology dynamics, demand dynamics, competition, and security as adjustment variables. Then, the evaluation model of network service based on network convergence is proposed and tested. The test results prove the validity of the evaluation model.

Keywords: Evaluation model, Network service, Networks convergence, SEM, Dynamic
\end{abstract}

\section{Introduction}

The feature of the world economy has transformed from large-scaled industrial production to new high tech like the information technology, and the industrial convergence mainly promoted by the information technology has become the new growth point of the world economy. Many countries provide support through legislation for the network convergence, and a series of policies have been put forward to encourage technological innovation and market competition. After more than a decade's development, a new convergence competition pattern forms. Convergence of the telecommunication network, the internet and the radio and television network has been basically implemented in some countries, which greatly promoted the development of information industry, and played a significant role in pushing the economic growth and promoting the social progress.

The development of network convergence fits to certain rules. The evolution of network convergence can be divided into four stages: Nicholas Negroponte (1973) [1] described the marginal overlay phenomenon of the computer industry, radio and movie industry, and the printing

\footnotetext{
* Correspondence: bupt_zhangj@163.com

School of Automation, Beijing University of Posts and Telecommunications, Beijing 100876, China
}

and publishing industry by using three overlapping circles. He indicated that the overlapping area is the field with the fastest developing speed and the brightest future vision. It is the first stage. In the 1980s, of the second stage, the concept of convergence of computer network, radio and television network, and telecommunication network was proposed. In the 1990s, of the third stage, network convergence referred to telecommunication network, radio and television network, and the Internet. With more and more attention being paid on the media prosperity of communication, network convergence refers to the convergence of telecommunication network, the Internet, and media network. The popularity of the mobile Internet and the stepping of the Internet of things from concept phase to implementation phase constantly expand the scope of the network, while continuing to promote the convergence of the network. Network convergence on the physical level refers to the transmission of voice, data, and images on the same network. For users, it means to realize the function of calling, watching TV, surfing the internet, and so on through the same access.

At present, the network convergence in China refers to that of the digital Internet represented by the Internet, the telecommunication network represented by the telephone network including the mobile communication network, 
and the radio and television network represented by the cable television network. The networks represent three different industries in the modern information industry, namely, the basic facility in the telecommunication industry, the internet industry, and the cable television industry. The current the network convergence does not mean the physical combination of the telecommunication network, the computer network, and the cable television network, but the application integration in business application. Technically, on the network level, the realization of mutual communication forms a seamless coverage. On the business level, mutual infiltration and crossing can be practiced. On the application level, the unified IP agreement can be used gradually. On the operation level, mutual competition and cooperation can be developed and crossed towards the same aim of providing diversified, mediatized, and personalized services. Finally, the industrial management and the policies can be gradually unified.

Traditionally, communication and media are completely different. However, with the development of technology, the boundaries between them are gradually becoming fussy. The communication becomes more important as a media method and the modern communication technology becomes a base of the new media, so the media prosperity of communication becomes increasingly emphasized.

In recent years, new media represented by the Internet develops fast. New media mainly refers to the media form which appears with the support system of new technologies. In addition to the Internet, it also includes digital magazine, mobile phone SMS, and the touch media. [2]. New media is completely different with the traditional one in form. It submerses the communication studies in the traditional meaning. The American magazine Wired gave a vivid definition of the new media as the transmission from all people to all people.

New media grows extremely fast from its production to its development. According to the definition given by an American transmission scholar that only when the using population of one media reaches the one fifth of the whole population around the country can it be referred to the public media. In America, the usage period of public media that reached the standard including the radio, the television (wireless), and the cable television is, respectively, 38, 13, and 10 years, but that of the Internet only takes 5 years. In China, according to the report data of iResearch Consulting, the new media accounted for 35\% of the media industry in 2012, in which the proportion growth compared to the same period of the network media including the network game and the network advertisement is $72.5 \%$. The growth speed is far more than that of the traditional media of $13.6 \%$, and the industrial scale of the new media industry expands quickly.

With the gradual deepening of the influence produced by the new media on the mainstream media, the network convergence can be promoted to a new stage until that of $\mathrm{N}$ networks [3]. The network convergence in the next stage may be practiced by taking the production, processing, transferring, and storage of information as the core. Through that, all kind of information including the data, video, and message can reach to any consumers through any physical network. Any legitimate information can get through the network easily. Data can be transferred, stored, and processed on the network. The intelligence trend of the network and the toolized degree become much higher; thus, the media prosperity of the communication network can be adequately represented. However, the $\mathrm{N}$ network convergence is the extension and development trend of the network convergence, which can make anyone enjoy any information service through any physical network. It would be the network that enables everyone's compound roles as the information producer, the propagator, and the consumer to be maximally realized.

From one network convergence to $\mathrm{N}$ network convergence, it is actually the direction of Ubiquity information development [4]. The ubiquity information refers to the intelligent comprehensive network information society, also the ubiquitous network society. In 1994, Japanese scholar Tadao Umesao proposed the concept of information society [5]. With the development of almost half a century, the information society is developed towards the direction of the ubiquitous intelligent comprehensive network information society, namely, the $\mathrm{U}$ information direction.

Currently, the technologies represented by the Bluetooth, RFID, WiFi, 4G, and the Internet of things are mutually converged with the ADSL and the FTTH networks [6]. Users can obtain information in the forms of text, voice, picture, and so on through the ubiquitous networks including the fixed telephone, the mobile telephone, the television, the computer, and diversified informational zed terminal equipment. $U$ information direction is the trend of future network development, which is the development direction of the ubiquitous intelligent comprehensive network information society. Its physical representation is the appearance of ubiquitous network or the named universal network. It represents the ubiquitous prosperity that all people, all organizations, and industries can get benefits from the $\mathrm{U}$ information direction.

As Internet applications become more sensitive to latency time, the needs for network management increase. Different applications need different levels of QoS for Internet access services decided by consumer preferences [7]. Solutions for future mobile front haul networks, as well as those for future convergence of the mobile front haul with optical broadband access networks, are frequently discussed [8]. The concept of network convergence for providing the overall architectural framework to bring together all the different technologies within a unifying and coherent network 
ecosystem has been proposed in the background of future $5 \mathrm{G}$ services vision [9].

Network convergence is the necessary trend for the development of the global information, with the basic reason as the progress of information technology and the pursuing for network scope economy from the network industry. This article studies the evolution of internal and external structures of network service model under the background of network convergence and introduces technology dynamics, demand dynamics, competition, and security as adjustment variables. Then, the evaluation model of network service based on network convergence is proposed and the test is implemented to prove the validity of the evaluation model.

\section{Methods and tools}

The paper applies the analysis technology of structural equation model (SEM) to test the hypotheses in the research. Structural equation model invokes a measurement model that defines latent variables using one or more observed variables and a structural model that imputes relationships between latent variables. The model consists of latent variables, measured variables, and a path. Latent variables cannot be directly observed but are rather inferred from other variables. Measured variables (manifest variable) can be directly measured and are usually used to explain latent variables [10].

In the analysis process of SEM, the first problem to be judged is the validity of the measurement model, meaning whether the observation variables can be measured to define the corresponding latent variables; otherwise, the analyzed result through the SEM method would be invalid. Therefore, the trust and efficiency evaluation problem of the measurement table are involved.

\subsection{Reliability test}

The measurement model part in the SEM model includes the latent variables and several observable variables used to test the latent variables (shown variables). The internal consistency between the tested items is an index to be measured. To carry out the trust test for the variables is a significant aspect in the evaluation of the SEM model.

To make the reliability test on the variables is an important aspect in the evaluation of the SEM model. Cronbach's alpha is used often to test to what degree can the observed variables belong to the same group [11]. Therefore, this paper first carried out the reliability test on the questionnaire, meaning to verify the internal consistency between the tested items to evaluate the reliability of the measurement table through adopting the method of Cronbach's alpha. The coefficients are used as the trust evaluation indexes, and the software of SPSS is used to finish the reliability test of the measurement table.

\subsection{Factor analysis}

The principle of the factor analysis can be explained as follows. In a research, some unrelated comprehensive indexes may be used to analyze each kind of information in the variables. These comprehensive indexes are called factors. The factor analysis is to describe the relationship between many indexes or elements by several factors, indicating to reflect most information only by several factors. When testing the SEM model, this paper sets up two or more observation variables, which are subordinate to a certain potential variable, and then, the trust and efficiency of this kind of variable design is tested.

In this study, potential variables are designed in the SEM model, and each potential variable can be measured by several observable variables. Then, whether these measurement items can really reflex the real features of the measured potential variables requires a factor analysis. The result of the factor analysis on the measurement table can reflect the structural efficiency, while the main evaluation indexes include the factor loading and the cumulative explaining variance. The factor loading represents the relative degree between the original variable and some certain common factor. The cumulative explaining variance indicates the cumulative effective degree of the common factor to the measurement table or model.

\subsection{Descriptive statistics and simple correlation analysis}

Structural equation model analysis is based on relative coefficients, and the obvious correlation between variables is required. So, to make the correlation analysis on the variables is the premise of carrying out the SEM analysis.

The descriptive statistical analysis mainly checks the mean and the standard derivation of the collected data. The standard derivation shows the average discrete degree of a group of data around the average. The higher the standard derivation, the higher the difference degree of the variables is. The Pearson correlation coefficients are used in analyzing the correlation degree between each variable, and the values of these correlation coefficients should be between -1 and 1 . A positive value shows a positive relationship, while a negative value indicates a negative relationship. The higher the absolute value, the higher degree of correlation it shows [12].

The analyzing tools of this paper include AMOS7.0 and SPSS16.0. AMOS7.0 is a software package that uses the potential variables based on the variance matrix structure to evaluate the structure model. This method tests the mutual relationship between variables (whether the relationship is direct, indirect, or rational or irrational) through a multi-level analysis. It applies to the models with potential variables for indicating the mutual relationships and testing the model convergence.

From the above introduction, we can see that using the structural equation model technology and the AMOS 
software package is beneficial for analyzing the proposed problems in this paper. First, the structural equation model reflects not only the separate relationship between the elements in the model but also the mutual influence between them. Second, using the software package of AMOS7.0 to make an analysis can give a full play to the multi-route analysis of this method for presenting the features between variables' relationship. The clear route of AMOS can help to understand the structural equation model and avoid the interferences brought by measurement errors in a better way.

The survey includes two stages. First, we carry out a small-range questionnaire survey in three representative enterprises. Fifty pieces of questionnaires were provided, and 34 pieces were fed back, with the collecting proportion of $68 \%$. Second, we conducted a larger and more extensive survey in Beijing, Changsha, and Shanghai, with more than 500 pieces of questionnaire being provided, while 397 pieces have been collected back, taking a proportion of $79.4 \%$. Among the collected questionnaires, 350 pieces are valid, and the validity proportion is $88.2 \%$.

\section{3. Variable measure and test}

\subsection{Variable measure}

This paper measure the latent variables by using external, internal [13], and adjustment factors [14-17] that influence the selection of network service model under network convergence, see Tables 1, 2, and 3.

\subsection{Reliability test}

The reliability test result of external elements of the service model based on network convergence is shown as follows in Table 4. Cronbach's $\alpha$ coefficient values of the capital market, the consumer demand, the technical progress, and the enterprise innovation capability are, respectively, 0.699, 0.738, 0.709, and 0.678. The total Cronbach's $\alpha$ coefficient is 0.785 , showing that the trust degree can basically research or surpass the acceptance level of 0.7 suggested by Nunnally (1994) [18], and there is a high degree of internal consistency of the external factor measurement scale. The correlation value of each separate item to the general item should reach 0.4. According to the standard proposed by Tian (2001) [19], an item with a coefficient value of less than 0.4 should be removed. Therefore, X6 and X13 are removed.

The reliability test result of internal variables is shown in Table 4. The correlation coefficient of item y6 in the value creation to the overall dimension is 0.369 , and that of item y15 in the interface rule is 0.231 , which are lower than the standard of 0.4; therefore, the two items are removed. Cronbach's $\alpha$ coefficient values of the value proposition, the value creation, the value transfer, and the interface rule are, respectively, 0.802, 0.796, 0.799, and 0.805 , which surpass the acceptance trust level of 0.7. It indicates the high internal consistency of the internal factor measurement table.

\subsection{Validity test}

$\mathrm{KMO}$ is usually used to evaluate the adaptation of the sample. Before carrying out the factor analysis, the KMO value should be tested. A sound KMO value represents that the collected sample fit to the factor analysis. According to the study by Kaiser [20], if the value of KMO is smaller than 0.5 , then the adaptation of the sample is not good and only when the KMO value is larger than 0.6 can the factor analysis be valid.

Table 5 shows the test results of the KMO and the Bartlett sphericity test of the four items that are used to evaluate the external environmental factors in the

Table 1 External variables measure of network service model

\begin{tabular}{lll}
\hline First-level index & Second-level index & Measuring questions \\
\hline External factors & Capital market & The service model regulation be supported by the capital market (X1) \\
& The capital market provide sufficient exit channels for the risk investment used in the service model \\
regulation (X2) & The consumer demand have profound influence to the service model of the enterprise (X3) \\
& Enterprise understands consumers' life style and promotes new services to satisfy their expectation (X4) \\
& Enterprise changes the current service model trough improving their technologies (X5) \\
Technical progress & The society encourages the atmosphere of innovation which plays a promotion effect to the innovation \\
of the enterprise service model (X6) & Make clear the industrial development direction, and know how to change to influence the enterprise (X7) \\
Innovation capability & Search for opportunities in fields that have never entered (X8) \\
& Be capable of evaluating each opportunity and making decision through combining the internal \\
conditions of the enterprise itself (X9) & Keep searching for newly expanded markets and methods of selling products and services (X10) \\
& The enterprise takes the initiative to explore the current and the future market (X11)
\end{tabular}


Table $\mathbf{2}$ Internal variables measure of network service model

\begin{tabular}{|c|c|c|}
\hline First-level index & Second-level index & Measuring questions \\
\hline \multirow[t]{15}{*}{ Internal factors } & \multirow[t]{3}{*}{ Value proposition ( $(1)$} & The enterprise defines target customers clearly with uniquely consistent value proposition (y1) \\
\hline & & The enterprise can keep exploring consumers' new demands (y2) \\
\hline & & $\begin{array}{l}\text { The enterprise proposes new value propositions based on the changes of its strategic resources and core } \\
\text { capabilities (y3) }\end{array}$ \\
\hline & \multirow[t]{4}{*}{ Value creation (n2) } & The provided value to customers by the enterprise has new changes (y4) \\
\hline & & The enterprise adapts new methods for obtaining profits (y5) \\
\hline & & The enterprise has a good position in the industrial chain and obtains main profits in the value chain (y6) \\
\hline & & Compared with other companies, the profit model of the enterprise has more advantages (y11) \\
\hline & \multirow[t]{2}{*}{ Value transfer (n3) } & The enterprise creates a new model of the marketing channel (y7) \\
\hline & & The enterprise's methods in contacting and maintaining consumers change (y8) \\
\hline & \multirow[t]{2}{*}{ Value network (n4) } & The enterprise cooperation network updates and explores, while emphasizing the win-win target (y9) \\
\hline & & $\begin{array}{l}\text { The enterprise can improve its capability through obtaining new information, resources and markets from } \\
\text { the value network, or through studying }(y \mid 0)\end{array}$ \\
\hline & \multirow[t]{4}{*}{ Interface rule (n5) } & $\begin{array}{l}\text { The enterprise establishes a synergistic mechanism for all parts of its service model to prevent the external } \\
\text { imitation (y12) }\end{array}$ \\
\hline & & $\begin{array}{l}\text { The enterprise breaks the normal component complex of the service model, and the interface combination } \\
\text { of the business activities and distribution is different from other enterprises in the industry (y13) }\end{array}$ \\
\hline & & The enterprise innovates the components and interface rules of the service model (y14) \\
\hline & & Generally, the service model of the enterprise is innovative (y15) \\
\hline
\end{tabular}

service model selection. The KMO value is 0.698 , and the accompany probability from the Bartlett sphericity test is 0.000 , which is smaller than the obvious level of 0.05 , so the test rejects the zero hypothesis of the Bartlett sphericity test, holding that it fits to the factor analysis.

Table 6 shows the factor analysis result of the internal environmental factors in the service model selection. The result of the factor analysis on the nine items shows that they have a significant factor load coefficient on four common factors. It can be seen that the two items of capital market support, three items of the consumer demand, two items of the technical progress, and two items of the industrial development are separately positioned in four different common factors, indicating that the four dimensions are the dimensions of influencing factors in different service model selections. Generally, the four dimensions are mutually independent. The sample date result reflects the independency of the capital support, the consumer demand, the technical progress, and the industrial development well.

The result of the KMO and the Bartlett sphericity test on 15 items of the internal structure shows the value of $\mathrm{KMO}$ is 0.666 . According to the standard given by the statistic scientist Kaiser, when the value is larger than 0.6, it shows the sound adaptation to carry out the factor analysis. The accompany probability of the Bartlett sphericity test is 0.000 , which is smaller than the significance level of 0.05 , so the zero hypothesis of the Bartlett sphericity test is rejected, indicating that it fits to the factor analysis.
Table 7 shows the factor analysis result of the internal structure of the service model selection. The result of the factor analysis on the 15 items shows that they have a significant factor load coefficient on five common factors. It can be seen that the three items of value proposition, three items of the interface rule, three items of the value transfer, three items of the value creation, and two items of the value network are separately positioned in five different common factors, indicating that the five dimensions are the different service model dimensions. Generally, the five dimensions are mutually independent. The sample date result reflects the independency of the value proposition, interface rule, value transfer, value creation, and value network well.

\section{Results and discussion}

The structural equation model includes the measurement model and the structure model. The former describes the relation between the obvious variables and the potential variables, indicating the observable variables of the potential variables [10]. The simple measurement model is the confirmed factor analysis model. The calculation result of the measurement model, which is the load coefficient between the factor and the index, shows the explaining degree of the measurement index to the total variable of the factor. Meanwhile, the statistical significance of the load coefficients is judged, which is also the $t$ value.

To judge whether a model can be accepted in the testifying factor analysis, the analysis of the model fitting 
Table 3 Environmental adjustment variables measure of network service model

\begin{tabular}{|c|c|c|}
\hline Fist-level index & Second-level index & Measuring questions \\
\hline \multirow[t]{7}{*}{ Competitive advantages } & $\mathrm{C} 1$ & Compared with rivals, the sales income of the enterprise grows faster \\
\hline & $\mathrm{C} 2$ & Compared with rivals, the market share expands in a larger degree \\
\hline & C3 & Compared with rivals, the investment return radio is higher \\
\hline & C4 & Compared with rivals, the cost saving is larger \\
\hline & C5 & Compared with rivals, the new selling points grow faster \\
\hline & C6 & Compared with rivals, the consumer growth ratio is higher \\
\hline & $\mathrm{C7}$ & Compared with rivals, the employee growing ratio is higher \\
\hline \multirow[t]{5}{*}{ Technical dynamics } & t1 & In the service field of the enterprise, technologies change quickly \\
\hline & t2 & Technical changes can provide good opportunities for the service development in the enterprise \\
\hline & t3 & $\begin{array}{l}\text { It is hard to forecast what kind of technology will be in the leadership in the current service field } \\
\text { of the enterprise }\end{array}$ \\
\hline & t4 & A series of new businesses in the service field of the enterprise may appear \\
\hline & t5 & $\begin{array}{l}\text { In the service field of the enterprise, technological development is not significant for the enterprise } \\
\text { development }\end{array}$ \\
\hline \multirow[t]{5}{*}{ Demand dynamics } & m1 & In the service market, the consumer preference changes quickly \\
\hline & $\mathrm{m} 2$ & The current consumers of the enterprise are tend to search for new products and services \\
\hline & m3 & Lots of new consumers are requiring for the enterprise products \\
\hline & m4 & New customers mainly come from the improvement of the enterprise products and services \\
\hline & m5 & The resource distribution of the company tends to satisfy the demands of current consumers \\
\hline \multirow{4}{*}{$\begin{array}{l}\text { Environmental } \\
\text { competitiveness }\end{array}$} & d1 & The services and consumers of the enterprise show a variety feature \\
\hline & $d 2$ & $\begin{array}{l}\text { Differences between the purchasing habits of consumers and the products or services of the } \\
\text { enterprise (the same big difference) }\end{array}$ \\
\hline & d3 & Competition in the enterprise products or services (the same big difference) \\
\hline & d4 & In the enterprise products and services, the market changing and uncertainty exist \\
\hline \multirow[t]{3}{*}{ Environmental security } & s1 & The threat degree of enterprises in the operational environment (security threat) \\
\hline & s2 & The presentation of enterprise' operational environment in the opportunity, resource, and competition \\
\hline & s3 & $\begin{array}{l}\text { The influence of factors such as competition, politics, and technology to the enterprise operational } \\
\text { management (whether the enterprise can master the influence or cannot master it) }\end{array}$ \\
\hline
\end{tabular}

should be made for judging the validity of the model. The frequently used fitting indexes include the $X^{2}$ of the chi-square test and $\chi^{2} / d f$ test, root mean square error of approximation (RMSEA), standard root mean square residual (SRMR), Normal Fit Index (NFI), Comparative Fit Index (CFI), GFI, and AGFI.

\subsection{Evaluation model of internal factors}

According to the proposed concept model and the research hypotheses in the former part of this paper, the AMOS7.0 software is used to represent the structural equation model of the internal factors adopted in the service model selection. It can show clearly the contained variables and the variable structure in this research.

The parameter estimation of the SEM model in this paper adapts the method of maximum likelihood estimation, and the model evaluation and revision are carried out from the following three aspects. First, use each fitting index to make an overall evaluation of the model. This research mainly checks the degree of freedom, the chi-square value, the CFI, the NFI, and the RMSEA. Secondly, test the significance of the parameter, the meaning and rationality of the evaluation parameters, such as the coefficient of each route, the residual value, and the statistical significance. Thirdly, determine the statistic value of the variable model fitting degree.

Table 8 shows the overall fitting statistic value of the original model. Here, the representatives of the absolute fitting indexes include the chi-square value $\chi^{2}=535.232$, and the degree of freedom $d f=128$, and then the ratio of $\chi^{2} / d f=4.179$. The ratio value is between 2.0 and 5.0, indicating that the model is acceptable. The value of RMSEA is 0.098. Steiger (1980) [21] believed that when the value of RMSEA is lower than 0.1, it shows a good fitting degree; when it is lower than 0.05 , the fitting degree is better; and when the degree is lower than 0.01 , the fitting degree is excellent. The value of CFI and NFI is all more than 0.9, achieving the requirement level of incremental fit. The above indexes all reflect that the 
Table 4 Results of reliability test

\begin{tabular}{|c|c|c|c|c|}
\hline & $\begin{array}{l}\text { Measuring } \\
\text { questions }\end{array}$ & $\begin{array}{l}\text { Correlation of } \\
\text { separate item } \\
\text { to general item }\end{array}$ & $\begin{array}{l}\text { Value of } a \text { after } \\
\text { removing this } \\
\text { item }\end{array}$ & $\begin{array}{l}\text { Cronbach's } \\
\text { a coefficient }\end{array}$ \\
\hline \multirow{17}{*}{$\begin{array}{l}\text { External } \\
\text { variables }\end{array}$} & Variable 1 & & & .699 \\
\hline & $x 1$ & .403 & .708 & \\
\hline & $\times 2$ & .481 & .774 & \\
\hline & Variable 2 & & & .738 \\
\hline & $\times 3$ & .437 & .708 & \\
\hline & $X 4$ & .480 & .762 & \\
\hline & X9 & .539 & .780 & \\
\hline & Variable 3 & & & .709 \\
\hline & $\times 5$ & .496 & .759 & \\
\hline & $x 8$ & .454 & .721 & \\
\hline & Variable 4 & & & \\
\hline & X6 & .102 & .667 & Remove X6 \\
\hline & Variable 5 & & & .678 \\
\hline & $X 7$ & .495 & .675 & \\
\hline & $\times 10$ & .064 & .715 & Remove $\times 10$ \\
\hline & $X 11$ & .504 & .671 & \\
\hline & $\begin{array}{l}\text { General value } \\
\text { (11 items) }\end{array}$ & & & .785 \\
\hline \multirow{21}{*}{$\begin{array}{l}\text { Internal } \\
\text { variables }\end{array}$} & Variable 1 & & & .802 \\
\hline & Y1 & .596 & .792 & \\
\hline & Y2 & .680 & .795 & \\
\hline & Y3 & .609 & .799 & \\
\hline & Variable 2 & & & .796 \\
\hline & Y4 & .547 & .793 & \\
\hline & Y5 & .662 & .787 & \\
\hline & Y6 & .640 & .793 & \\
\hline & Y11 & .369 & .787 & \\
\hline & Variable 3 & & & .799 \\
\hline & Y7 & .506 & .790 & \\
\hline & Y8 & .551 & .792 & \\
\hline & Y9 & .640 & .796 & \\
\hline & Variable 4 & & & \\
\hline & Y10 & .616 & .795 & \\
\hline & Variable 5 & & & .805 \\
\hline & Y12 & .578 & .802 & \\
\hline & Y13 & .644 & .799 & \\
\hline & Y14 & .660 & .799 & \\
\hline & Y15 & .231 & .802 & \\
\hline & $\begin{array}{l}\text { General value } \\
\text { (15 items) }\end{array}$ & & & .807 \\
\hline
\end{tabular}

Table $5 \mathrm{KMO}$ sample measurement and the Bartlett sphericity test

\begin{tabular}{lll}
\hline Kaiser-Meyer-Olkin sample adequacy & .698 \\
\hline Bartlett sphericity test & Chi-square value & 1185.734 \\
& Degrees of freedom & 153 \\
& Significance probability & .000 \\
\hline
\end{tabular}

model of the internal influencing factors in the service model selection has a good fitting degree.

As seen from the data result in Table 9, we get that most indexes have a statistical significance when the factor load coefficient satisfies the condition of $p<0.05$, indicating that each index has a high explaining degree to the total variance of the factor, also that the observed variables can finely explain the potential variables. From the route coefficient table, it can be seen that there are two routes that have passed the significance test.

\subsection{Evaluation model of external factors}

According to the proposed concept model and the research hypotheses in the former part of this paper, the AMOS7.0 software is used to represent the structural equation model of the external factors adopted in the service model selection. It can show clearly the contained variables and the variable structure in this research.

The overall evaluation of the model in this paper also adapts the method of max likelihood estimates and a variety of fitting indexes.

Table 10 shows the overall fitting statistic value of the external influencing factor model. Here, the representatives of the absolute fitting indexes include the chisquare value $\chi^{2}=1699.9$, the degree of freedom $d f=350$, and then the ratio of $\chi^{2} / d f=4.86$. The ratio value is between 2.0 and 5.0, indicating that the model is acceptable. The value of NFI is 0.832 , showing a good fitting

Table 6 Factor analysis result of influencing factors

\begin{tabular}{lrrrr}
\hline Items & Factor 1 & Factor 2 & Factor 3 & Factor 4 \\
\hline X1 & .537 & & & \\
X2 & .524 & & & \\
X3 & & .812 & & \\
X4 & & .507 & & \\
X5 & & & .716 & \\
X7 & & & & .683 \\
X8 & & & .844 & \\
X9 & & .531 & & \\
X11 & & & & .501 \\
Eigen value & 2.105 & 1.995 & 1.382 & 1.358 \\
The explained variance percentage & 12.696 & 12.085 & 17.679 & 17.542 \\
The cumulative explained variance & 12.696 & 24.781 & 42.460 & 60.002 \\
\hline
\end{tabular}

Note: Adopt the principal component extraction method, and the rotation method uses the Varimax with Kaiser normalization to rotate for 12 times 
Table 7 Factor analysis of internal structure

\begin{tabular}{lrrrr}
\hline Items & Factor 1 & Factor 2 & Factor 3 & Factor 4 \\
\hline Y1 & .712 & & & \\
Y2 & .848 & & & \\
Y3 & .609 & & & \\
Y4 & & .667 & & \\
Y5 & & .528 & & \\
Y11 & & .797 & & \\
Y7 & & & .504 & \\
Y8 & & & .647 & \\
Y9 & & & .795 & \\
Y10 & & & & .807 \\
Y12 & & & & .765 \\
Y13 & & & & .781 \\
Y14 & & & & .707 \\
Eigen value & & & & 1.699 \\
The explained variance percentage & 14.67 & 12.26 & 12.83 & 11.33 \\
The cumulative explained variance & 14.67 & 26.93 & 39.76 & 51.09 \\
\hline
\end{tabular}

Note 1: Adopt the principal component extraction method, and the rotation method uses the Varimax with Kaiser normalization to rotate for 12 times

Note 2: Factor 1 is the value proposition, factor 2 is the value creation, factor 3 is the value transfer, factor 4 is the value network and factor 5 is the interface rule

degree. The comparative fitting index belongs to the third type of comparative fitting indexes, which also uses the expectation value of the chi-square of the theoretical model or the standard model under the non-central chisquare distribution for regulation besides the first type of information. The CFI value is 0.859 , reflecting a good fitting degree.

Table 11 shows the data result of the factor load coefficients and the corresponding C.R. value between each potential variable and the potential variable in the measurement model. Use the fixed load method, and the calculation result show that the route coefficients of the three elements of capital support, consumer demand, and technical progress have passed the test with a statistical significant under the condition of $p<0.05$.

\subsection{Discussion of adjustment variables}

Based on the features of the environment faced up by the network enterprises in the network convergence, this paper will select the environmental variables from the

Table 8 Fitting degree of the internal structure model

\begin{tabular}{ll}
\hline Degrees of freedom & 128 \\
\hline Chi-square value of $X^{2}$ & 535.232 \\
CFI & 0.913 \\
$\mathrm{NFI}$ & 0.927 \\
RMSEA & 0.098 \\
\hline
\end{tabular}

Table 9 Evaluation of the internal structure

\begin{tabular}{lllll}
\hline Indexes & Estimate & S.E. & C.R. & $P$ \\
\hline Competitive advantages $\longleftarrow$ value proposition & .069 & .096 & .713 & .476 \\
Competitive advantages $\longleftarrow$ value transfer & .888 & .237 & 3.740 & $* * *$ \\
Competitive advantages $\longleftarrow$ value creation & .050 & .159 & .316 & .752 \\
Competitive advantages $\leftarrow$ interface rule & .327 & .157 & 2.083 & .037 \\
${ }^{* * *} p<0.001$ & & & &
\end{tabular}

four dimensions such as the technical change, the market change, the environmental competition, and the environmental security. The analysis of this part involves the dependent variable, the independent variable, and the regulation variable. Here, the dependent variable is the competitive advantages (CA) of enterprises, and the independent variables are the value proposition (X1), the value creation (X2), the value transfer $(\mathrm{X} 3)$, and the interface rule (X4).

Suppose the dependent variable of the enterprise's competitive advantage (CA) is a linear function of multiple independent variables of $\mathrm{X} 1, \mathrm{X} 2, \ldots . . \mathrm{Xn}$ and the error term, we get the multiple linear regression model as follows:

$$
C A=\beta 0+\beta 1 X 1+\beta 2 X 2+\beta 3 X 3+\beta 4 X 4+\varepsilon
$$

Here, CA is the dependent variable; $\mathrm{X} 1, \mathrm{X} 2, \mathrm{X} 3$, and $\mathrm{X} 4$ are the independent variables; and $\varepsilon$ is a random disturbance term.

This part divides the sample into two statuses according to the technical dynamics, the demand dynamics, the environmental competitiveness, and the security. One is with high changing frequency with a measurement value larger than 4 , and the other is with low changing frequency with a measurement value smaller than 4 . When the measurement value equals to 4 , it would be neglected. Then, the multiple linear regression analysis on effective samples is carried out, see Tables 12, 13, 14, and 15.

As seen from the Table 12, we get that in the environment with high changing frequency, the value proposition and the competitive advantages of enterprises are negatively related, while being positively related with other elements, and in the environment with low changing frequency, the value proposition and value transfer and the competitive advantages of enterprises are positively related, but being invalid in the significance test

Table 10 Fitting degree of the external structure model

\begin{tabular}{ll}
\hline Degrees of freedom & 350 \\
\hline Chi-square value of $x^{2}$ & 1699.9 \\
CFI & 0.859 \\
NFI & 0.832 \\
RMSEA & 0.10 \\
\hline
\end{tabular}


Table 11 Evaluation of the internal structure

\begin{tabular}{llllll}
\hline Indexes & Estimate & S.E. & C.R. & $P$ \\
\hline Service model selection capital support & .274 & .089 & 3.068 & .002 \\
Service model selection consumer demand & .586 & .132 & 4.433 & ${ }^{* * *}$ \\
Service model selection technical progress & .531 & .149 & 3.674 & ${ }^{* * *}$ \\
Service model selection industrial development & .668 & .802 & .833 & .405 \\
${ }^{* * *} p<0.001$ & & & & &
\end{tabular}

$(p \leq 0.05)$, while the value transfer and the interface rule are negatively related to the CA. Meanwhile, with the technical changing degree changes from a low level to a high level, the relation degree of the service and the enterprise's competitive advantage increases, indicating that the technologies change faster and the influence of the service model selection to the company's competitive advantage would be larger.

Therefore, the technological change can influence the relationship between the service model and the competition advantages of enterprises, and in the environment with high technology changing frequency, the service model that has more significant influence to the competition advantages can be confirmed.

As seen from the Table 13, we get that in the environment with high changing frequency, the value proposition, value creation, value transfer, and the interface rule positively relate to the competitive advantage of enterprises, but the value proposition and the value creation have not passed the significance test $(p \leq 0.05)$. In the environment with low changing frequency, the value proposition, value creation, value transfer, and the interface rule positively relate to the competitive advantage of enterprises, while the interface rule negatively relate to the CA. Meanwhile, with the technical changing degree changes from a low level to a high level, the relation degree of the service model and the enterprise's competitive advantage increases, indicating that the market changes faster and the

Table 12 Regression model fitting of technical dynamics

\begin{tabular}{|c|c|c|c|c|}
\hline & \multicolumn{2}{|c|}{ High changing frequency } & \multicolumn{2}{|c|}{ Low changing frequency } \\
\hline & $\begin{array}{l}\text { Standardized } \\
\text { coefficients }\end{array}$ & Significance & $\begin{array}{l}\text { Standardized } \\
\text { Coefficients }\end{array}$ & Significance \\
\hline $\begin{array}{l}\text { Value } \\
\text { proposition }\end{array}$ & -.389 & .001 & .366 & .072 \\
\hline Value creation & .377 & .000 & -.806 & .000 \\
\hline Value transfer & .555 & .000 & .525 & .078 \\
\hline Interface rule & .167 & .030 & -.311 & .003 \\
\hline$R$ square & \multicolumn{2}{|c|}{0.891} & \multicolumn{2}{|c|}{0.770} \\
\hline $\begin{array}{l}\text { Adjusted } \\
R \text { square }\end{array}$ & \multicolumn{2}{|c|}{0.875} & \multicolumn{2}{|c|}{0.723} \\
\hline
\end{tabular}

Predictors (constant): value proposition, value creation, value transfer, and interface rule

Dependent variable: $\mathrm{CA}$
Table 13 Regression model fitting of demand dynamics

\begin{tabular}{|c|c|c|c|c|}
\hline & \multicolumn{2}{|c|}{ High changing frequency } & \multicolumn{2}{|c|}{ Low changing frequency } \\
\hline & $\begin{array}{l}\text { Standardized } \\
\text { coefficients }\end{array}$ & Significance & $\begin{array}{l}\text { Standardized } \\
\text { coefficients }\end{array}$ & Significance \\
\hline $\begin{array}{l}\text { Value } \\
\text { proposition }\end{array}$ & .014 & .063 & .495 & .000 \\
\hline Value creation & .126 & .121 & .104 & .039 \\
\hline Value transfer & .496 & .000 & .623 & .000 \\
\hline Interface rule & .417 & .000 & -.459 & .000 \\
\hline$R$ square & \multicolumn{2}{|c|}{0.828} & \multicolumn{2}{|c|}{0.709} \\
\hline $\begin{array}{l}\text { Adjusted } \\
R \text { square }\end{array}$ & \multicolumn{2}{|c|}{0.795} & \multicolumn{2}{|c|}{0.701} \\
\hline
\end{tabular}

Predictors (constant): value proposition, value creation, value transfer, and interface rule

Dependent variable: $\mathrm{CA}$

influence of the service model selection to the company's competitive advantage would be larger.

Therefore, the market change can influence the relationship between the service model and the competition advantages of enterprises, and in the environment of high market changing, the service model that has more significant influence to the competition advantages can been confirmed.

As seen from the Table 14, we get that in the environment with high frequency of change, the value proposition negatively relates to the $C A$, while value creation, value transfer, and the interface rule positively relate to the CA. In the environment with low frequency of change, the value proposition, value creation, and interface rule positively relate to the $\mathrm{CA}$, while the value transfer negatively relates to the $C A$, but the value transfer did not pass the significance test $(p \leq 0.05)$. Meanwhile, with the technical changing degree changes from a low level to a high level, the relation degree of the service model and the enterprise's competitive advantage increases, indicating that the fiercer the competition degree, the influence of the service

Table 14 Regression model fitting of competitiveness

\begin{tabular}{|c|c|c|c|c|}
\hline & \multicolumn{2}{|c|}{ High changing frequency } & \multicolumn{2}{|c|}{ Low changing frequency } \\
\hline & $\begin{array}{l}\text { Standardized } \\
\text { coefficients }\end{array}$ & Significance & $\begin{array}{l}\text { Standardized } \\
\text { coefficients }\end{array}$ & Significance \\
\hline $\begin{array}{l}\text { Value } \\
\text { proposition }\end{array}$ & -.293 & .001 & .325 & .025 \\
\hline Value creation & .192 & .013 & .855 & .000 \\
\hline Value transfer & .663 & .000 & -.120 & .340 \\
\hline Interface rule & .241 & .001 & .614 & .001 \\
\hline$R$ square & \multicolumn{2}{|c|}{0.817} & \multicolumn{2}{|c|}{0.579} \\
\hline $\begin{array}{l}\text { Adjusted } \\
R \text { square }\end{array}$ & \multicolumn{2}{|c|}{0.751} & \multicolumn{2}{|c|}{0.557} \\
\hline
\end{tabular}

Predictors (constant): value proposition, value creation, value transfer, and interface rule

Dependent variable: $\mathrm{CA}$ 
Table 15 Regression model fitting of security

\begin{tabular}{|c|c|c|c|c|}
\hline & \multicolumn{2}{|c|}{ High changing frequency } & \multicolumn{2}{|c|}{ Low changing frequency } \\
\hline & $\begin{array}{l}\text { Standardized } \\
\text { coefficients }\end{array}$ & Significance & $\begin{array}{l}\text { Standardized } \\
\text { coefficients }\end{array}$ & Significance \\
\hline $\begin{array}{l}\text { Value } \\
\text { proposition }\end{array}$ & -.021 & .862 & -.218 & .186 \\
\hline Value creation & .156 & .219 & .620 & .002 \\
\hline Value transfer & .447 & .000 & .108 & .454 \\
\hline Interface rule & .113 & .307 & .478 & .019 \\
\hline$R$ square & \multicolumn{2}{|c|}{0.371} & \multicolumn{2}{|c|}{0.824} \\
\hline $\begin{array}{l}\text { Adjusted } \\
R \text { square }\end{array}$ & \multicolumn{2}{|c|}{0.334} & \multicolumn{2}{|c|}{0.780} \\
\hline
\end{tabular}

Predictors (constant): value proposition, value creation, value transfer, and interface rule

Dependent variable: $\mathrm{CA}$

model selection to the company's competitive advantage would be larger.

Therefore, the environment competition can influence the relationship between the service model and the competition advantages of enterprises, and in the environment of high competition degree, the service model has more significant influence to the competition advantages can be confirmed.

As seen from the Table 15, we get that no matter what the environmental degree is, the results of the significant test are not ideal. However, in the environment with low environmental security, the service model and the competitive advantage of enterprises show a better correlation. Therefore, the environment security can influence the relationship between the service model and the competition advantages of enterprises, and in the environment of low security, the service model that has more significant influence to the competition advantages can be denied.

\section{Conclusions}

Therefore, we conclude the following:

(1).The network convergence produces a profound influence to network service model. Network convergence promotes the expansion, extension, and refinement of network service chain and the innovation of the industrial form. Meanwhile, it makes the network service chain show the diversified subdivision and biological systematic features. Consumer requirements also change in the direction of personalization and diversification.

(2).The influence of the external structure to the network service model is evaluated by the influence they have to the component elements of the service model. The influence of the internal and adjusting structure to the service model is evaluated by their influence on the competitive advantages.

(3)Seen from the regulation variables, when it increases from a low level to a high level in aspects of the technical changing, the market changing, and the environment competition, the correlation degree between the enterprise's competitive advantage and the service model selection will also increase. In a different environment, different elements of the network service model will have influence of different degrees on the competitive advantages, thus providing basis for deciding the regulation strategies of the service model for enterprises in different environment, see Table 16.

(4).The network service model under network convergence has three characteristics, including space multidimensionality, network externalities, and system competitiveness, and the integration

Table 16 Influence of adjusting variables to network service model

\begin{tabular}{|c|c|c|}
\hline $\begin{array}{l}\text { Competitive environmental } \\
\text { changing }\end{array}$ & "+" positive related (influence degree) & "_" negative related (influence degree) \\
\hline Technical dynamic in high frequency & $\begin{array}{l}\text { Value creation (middle), value transfer (middle), } \\
\text { and interface rule (weak) }\end{array}$ & Value proposition (middle) \\
\hline Technical dynamic in low frequency & Null & $\begin{array}{l}\text { Value creation (strong) and interface } \\
\text { rule (middle) }\end{array}$ \\
\hline Demand dynamic in high frequency & value transfer (middle) and interface rule (middle) & Null strong \\
\hline Demand dynamic in low frequency & $\begin{array}{l}\text { Value proposition (middle), value creation (weak), } \\
\text { and value transfer (strong) }\end{array}$ & Interface rule (middle) \\
\hline Highly competitive & $\begin{array}{l}\text { Value creation (weak), value transfer (strong), } \\
\text { and interface rule (weak) }\end{array}$ & Value proposition (weak) \\
\hline Lowly competitive & $\begin{array}{l}\text { Value proposition (middle), value creation (strong), } \\
\text { and interface rule(strong) }\end{array}$ & Null \\
\hline High security & Value transfer (middle) & Null \\
\hline Low security & Value creation (strong) and interface rule(middle) & Null \\
\hline
\end{tabular}

Note: Under the condition that satisfies the significance test, this paper defines that when the standardized coefficients is larger than 0.65 , the influence degree is strong, when between 0.3 and 0.65 , the influence degree is middle, and when less than 0.3 , it is weak 
trend requests network service providers to establish a new service model based on the new environment such as transforming from a single-service model to a bilateral-service model, and develop mesh service model finally. The service model transformation can be realized by diversifying the profit source, transforming the profit center, changing the profit flow, reducing the platform cost, and other specific operating modes.

\section{Abbreviation}

4G: The fourth-generation communication system; ADSL: Asymmetric digital subscriber line; AGFI: Adjusted goodness-of-fit index; CFI: Comparative Fit Index; FTTH: Fiber to the home; GFI: Goodness-of-fit index; NFI: Normal Fit Index; RFID: Radio frequency identification; RMSEA: Root mean square error of approximation; SEM: Structural equation modeling; SRMR: Standard root mean square residual

\section{Acknowledgements}

Not applicable.

\section{Funding}

Not applicable.

\section{Availability of data and materials}

Not applicable.

\section{Authors' contributions}

Both authors contributed equally to this work. Both authors read and approved the final manuscript.

\section{Competing interests}

The authors declare that they have no competing interests.

\section{Publisher's Note}

Springer Nature remains neutral with regard to jurisdictional claims in published maps and institutional affiliations.

Received: 7 December 2017 Accepted: 27 January 2018

Published online: 13 February 2018

\section{References}

1. N Negroponte, Recent advances in sketch recognition (National computer conference \& exposition, New York, 1973), pp. 663-675

2. W Fruin, Noah, N Montfort, et al., The new media reader (MIT Press, Cambridge, 2003), pp. 663-677

3. Z Jianqiu, F Binxing, Theory, experience and information security of the three networks convergence (Beijing university of posts and telecommunications publishing house, Beijing, 2010)

4. Z Jianqiu, Z Jing, Industry value chain evolution and service model innovation of three networks convergence. J. Beijing Univ. Posts Telecommun. (Social Sciences Edition). 13(6), 19-24 (2011)

5. T Umesao, The age of spiritual industry. Dicenda Cuadernos De Filología Hispánica 57(6), 263-265 (1994)

6. J Gubbi, R Buyya, S Marusic, et al., Internet of things (IoT): A vision, architectural elements, and future directions. Future Generation Comput Syst 29(7), 1645-1660 (2013)

7. D Lee, J Shin, S Lee, Network management in the era of convergence: focusing on application-based quality assessment of internet access service. Telecommun. Policy 39(8), 705-716 (2015)

8. J-i Kani, J Terada, K-I Suzuki, et al., Solutions for future mobile front haul and access-network convergence. J Lightwave Tech 35(3), 527-534 (2017)

9. M Ruffini, Multidimensional convergence in future $5 \mathrm{G}$ networks. J Lightwave Tech 35(3), 535-549 (2017)

10. RB Kline, Principles and practice of structural equation modeling (Third Ed.) (Guilford Press, New York, 2011)

11. $\amalg$ Cronbach, Essentials of psychological testing (Harper \& Row, New York, 1990)

12. TA Brown, Confirmatory factor analysis for applied research (Guilford Press, New York, 2006)
13. R Amit, C Zott, Value creation in e-business. Strategic Manage J 22(6/7), 493-520 (2005)

14. JC Guan, RCM Yam, CK Mok, et al., A study of the relationship between competitiveness and technological innovation capability based on DEA models. Eur. J. Oper. Res. 170(3), 971-986 (2006)

15. HE Aldrieh, J Pfeffer, Environments of organizations. Ann Rev Sociol 2(1), 79-105 (1976)

16. GG Dess, DW Beard, Dimensions of organizational task environments. Adm Sci Quart 29(1), 52-73 (1984)

17. C Moorman, A S miner, The impact of organizational memory on new product performance. J. Mark. Res. 34(1), 91-106 (1997)

18. JC Nunnally, IH Bernstein, The theory of measurement error. Psychometric Theory 3, 209-247 (1994)

19. TK Tepper, WO Bearden, GL Hunter, Consumer's need for uniqueness: scale development and validation. J. Consum. Res. 28(6), 50-66 (2001)

20. Nalin asanka gamagedaraarachchilage, Steve Love, A game design framework for avoiding phishing attacks. Comput. Hum. Behav. 29(3), 706714 (2013)

21. JH Steiger, JC Lind, Statistically-based tests for the number of common factors. In paper presented at the annual meeting of the Psychometric Society. lowa City, (1980)

\section{Submit your manuscript to a SpringerOpen ${ }^{\circ}$ journal and benefit from:}

- Convenient online submission

- Rigorous peer review

- Open access: articles freely available online

- High visibility within the field

- Retaining the copyright to your article

Submit your next manuscript at $\gg$ springeropen.com 